УДК 621.396.67(045)

\author{
ИЛЬНИЦКИЙ Л. Я., ЩЕРБИНА О. А.
}

\title{
АНТЕННАЯ СИСТЕМА ДЛЯ ИЗМЕРЕНИЯ ПАРАМЕТРОВ ЭЛЕКТРОМАГНИТНОГО ПОЛЯ
}

\author{
Национальный авиационный университет, Украина, Киев, \\ 03680, пр-т Космонавта Комарова 1
}

\begin{abstract}
Аннотация. Представлена структурная схема универсальной антенной системы для измерения параметров электромагнитной волны. Описаны теоретические соотношения, на основе которых построена структура антенной системы. Приведен принцип действия антенны
\end{abstract}

Ключевые слова: измерительная антенна, характеристика направленности, действующая длина, коэффициентом усиления, поляризационные свойства антенны, радиомониторинг

\section{ВСТУПЛЕНИЕ}

Функционирование радиоэлектронных средств (РЭС) в современных условиях регламентируется рядом технических и организационных положений. Нарушение этих положений приводит к возникновению помех для совокупности радиоэлектронных устройств или систем. Для обеспечения безусловного выполнения правил и норм регламента радиосвязи всеми пользователями радиочастотного ресурса созданы государственные службы, которые контролируют параметры излучения РЭС и оснащаются аппаратурой для радиомониторинга электромагнитной обстановки.

Одним из основных элементов такой аппаратуры является измерительная антенна. По своей сути это первичный преобразователь, при внесении которого в электромагнитное поле возникает на выходных зажимах электродвижущая сила (ЭДС), однозначно связанная с параметрами поля. Связь между параметрами электромагнитного поля и ЭДС на выходе антенны определяется характеристикой направ- ленности, действующей длиной, действующей площадью, коэффициентом усиления и поляризационными свойствами антенны $[1,2]$.

Приведенные параметры измерительной антенны должны быть известны и определены с высокой точностью. Но даже если эти требования удовлетворяются, измерительная антенна высокого качества не гарантирует высокой точности измерения параметров электромагнитного поля. Это обусловлено тем, что параметры антенны определяют для случаев, когда исследуемая волна падает на антенну в направлении максимума диаграммы направленности. Если направление распространения волны не совпадает с максимумом диаграммы направленности, тогда возникают погрешности в измерениях напряженности электрического поля и параметров поляризации радиоволны.

Для устранения или минимизации этих погрешностей необходимо плоскость (линию) раскрыва антенны ориентировать перпендикулярно направлению падения электромагнитной волны. Изменение положения антенны, т.е. ее пространственная ориентация, в процес-

Электронный вариант статьи: http://radio.kpi.ua/article/view/S002134701401004X 